\title{
Applying QGIS software to manage database of street and house number in Binh Tho ward, Thu Duc district, Ho Chi Minh City
}

\author{
Xuan T. Vo*, Thy N. Nguyen, Linh D. T. Truong, Duy T. Nguyen, \\ Khoi H. Nguyen, \& Trang T. Nguyen \\ Faculty of Land and Real Estate Management, Nong Lam University, Ho Chi Minh City, Vietnam
}

\author{
ARTICLE INFO \\ Research Paper \\ Received: April 12, 2018 \\ Revised: May 22, 2018 \\ Accepted: July 17, 2018
}

\section{Keywords}

Address database

Land parcel

Python programming language

QGIS

Street name

\section{${ }^{*}$ Corresponding author}

Vo Thi Xuan

Email: 14124432@st.hcmuaf.edu.vn

\begin{abstract}
Today, the rapid development of urban areas has led to the explosion of data volumes in land use change. The present development of infrastructure and housing has caused many difficulties in urban management, especially information of street name and house number. Therefore, the management and provision of information of street name and house number in a scientific and effective way is an urgent demand for all agencies, organizations and individuals in our society. Geographic information system (GIS) is developing increasingly and continuously and applied in many fields; QGIS is a new open source code software with many features, considered as one of the most powerful tools in designing and analysizing spatial database. Applying this software to manage database of name street and housing number will be better in managing construction and infrastructure development in urban areas which are suitable with the strategy of establishing smart city and e-government in our city and nation. The results of this study showed that the present and oriental organization of address built successfully a database of streets name, houses number and used Python programming language in developing the tool to manage and look up the information with functions such as look up, update and map interaction of Binh Tho ward, Thu Duc district, Ho Chi Minh City. The test results indicate that this tool is very useful in managing and searching information on street name, house number related to information on land parcels' information on cadastral base.
\end{abstract}

Cited as: Vo, X. T., Nguyen, T. N., Truong, L. D. T., Nguyen, D. T., Nguyen, K. H., \& Nguyen, T. T. (2020). Applying QGIS software to manage database of street and house number in Binh Tho ward, Thu Duc district, Ho Chi Minh City. The Journal of Agriculture and Development 19(1), 96-108. 


\title{
Ứng dụng phần mềm QGIS quản lí cơ sở dữ liệu đường phố, số nhà tại phường Bình Thọ, quận Thủ Đức, thành phố Hồ Chí Minh
}

\author{
Võ Thị Xuân*, Nguyễn Ngọc Thy, Trương Đỗ Thùy Linh, Nguyễn Thanh Duy, \\ Nguyễn Hưng Khởi \& Nguyễn Thùy Trang
}

Khoa Quản Lý Đất Đai và Bất Động Sản, Trường Đại Học Nông Lâm TP.HCM, TP. Hồ Chí Minh

\section{THÔNG TIN BÀI BÁO}

Bài báo khoa học

Ngày nhận: 12/04/2018

Ngày chỉnh sửa: 22/05/2018

Ngày chấp nhận: 17/07/2018

\section{Từ khóa}

Cơ sở dữ liệu đường phố

Đường phố

Ngôn ngữ lập trình Python

QGIS

Thửa đất

* Tác giả liên hệ

Võ Thị Xuân

Email: 14124432@st.hcmuaf.edu.vn

\section{TÓM TẮT}

Quá trình xây dựng cơ sở hạ tầng, nhà cửa không ngừng đã gây ra nhiều khó khăn trong công tác quản lý nhà đất, xây dựng đô thị, trong đó thông tin về đường phố và số nhà là một trong những cơ sở mấu chốt trong công tác quản lý nhà nước. Vì vậy, quản lý và cung cấp thông tin này một cách khoa học và hiệu quả là nhu cầu cấp thiết. Hệ thống thông tin địa lý (GIS) không ngừng phát triển và được ứng dụng trong nhiều lĩnh vực; trong đó, QGIS là phần mềm mã nguồn mở mới được xem là công cụ hỗ trợ đắc lực trong việc thiết kế dữ liệu và phân tích không gian. Ứng dụng QGIS quản lí cơ sở dữ liệu đường phố, số nhà sẽ phục vụ tốt hơn công tác quản lý xây dựng đô thị và cơ sở hạ tầng tại địa phương phù hợp với chiến lược phát triển đô thị thông minh và chính quyền điện tử của thành phố và cả nước. Nghiên cứu đã xây dựng bộ cơ sở dữ liệu thuộc tính và ứng dụng ngôn ngữ lập trình Python xây dựng công cụ quản lý và tra cứu thông tin đường phố, số nhà cho phường Bình Thọ, quận Thủ Đức. Kết quả cho thấy công cụ hỗ trợ quá trình quản lý, tra cứu thông tin về đường phố, số nhà và thông tin về thửa đất rất thuận tiện và hiệu quả.

\section{1. Đặt Vấn Đề}

Ngày nay, gắn liền với việc phát triển đô thị và cơ sở hạ tầng, thông tin về đường phố và số nhà ở nước ta luôn có sự chuyển dịch và biến động không ngừng do công tác đặt số nhà thủ công, thô sơ, còn nhiều sai sót, không chủ động trong cập nhật và chỉnh lý. Các loại bản đồ, sổ sách tài liệu... liên quan đến đường phố, số nhà chưa được thống nhất, dữ liệu ở dạng giấy và dạng số nhưng còn ở dạng dữ liệu thô, lưu trữ cồng kềnh, tra cứu thông tin khó khăn, làm cho công tác quản lý đường phố, số nhà gặp nhiều vướng mắt và ít có hiệu quả. Vì vậy, việc cần thiết phải có được hệ thống thông tin về xây dựng và cơ sở hạ tầng, đặc biệt là thông tin về đường phố, số nhà nhằm phục vụ cho các mục đích quản lý thông tin hành chính sao cho khoa học, hợp lý, đúng yêu cầu kỹ thuật và chuẩn quy định của ngành là một thách thức.
Quận Thủ Đức, Thành phố Hồ Chí Minh là địa bàn luôn có nhiều biến động phức tạp về đất đai, xây dựng nên việc xây dựng một bộ cơ sở dữ liệu về đường phố, số nhà đầy đủ, chính xác cùng một bộ công cụ hiệu quả để phục vụ công tác quản lý xây dựng, đô thị và cơ sở hạ tầng tại địa phương là nhiệm vụ vô cùng cấp thiết hiện nay.

Đã có rất nhiều phần mềm được ứng dụng nhằm cải cách và hiện đại hóa ngành quản lý đất đai, đặc biệt là các phần mềm thuộc hệ GIS, và một trong những ứng dụng quan trọng đó chính là những tính năng của phần mềm QGIS (trước đây gọi là phần mềm Quantum GIS). Theo Nguyen (2014), QGIS là một phần mềm của GIS mã nguồn mở tương đối mạnh và dễ sử dụng, được ứng dụng cho việc (1) tạo lập, chỉnh sửa, hiển thị, phân tích, xuất bản thông tin; (2) duyệt và xem dữ liệu và siêu dữ liệu; (3) kiểm soát lựa chọn các thuộc tính hoặc cách bố trí bản đồ và hệ tọa độ của những lớp dữ liệu; (4) phân tích không 
gian nhờ PostGIS hoặc kết nối với GRASS; và (5) thay đổi các tính năng thông qua cơ chế plug-in... Do vậy, ứng dụng QGIS trong quản lý cơ sở dữ liệu đường phố và số nhà là một giải pháp hữu hiệu.

Mục tiêu nghiên cứu: Chuẩn hóa bộ cơ sở dữ liệu đường phố, số nhà và ứng dụng phần mềm QGIS xây dựng công cụ quản lý, tra cứu thông tin đường phố, số nhà trên địa bàn nghiên cứu phục vụ hiệu quả trong công tác quản lý đô thị hướng đến chiến lược xây dựng cơ sở dữ liệu phát triển đô thị thông minh và chính quyền điện tử của Thành phố Hồ Chí Minh. Đối tượng áp dụng: đáp ứng nhu cầu sử dụng của các cơ quan quản lý nhà nước có liên quan.

\section{Vật Liệu và Phương Pháp Nghiên Cứu}

\subsection{Phương tiện nghiên cưu}

Nghiên cứu đã sử dụng các phương tiện như sau: Google Map, MicroStation - Famis, Microsoft Access, ArcGIS, QGIS, MapInfo Profesional, Ngôn ngữ lập trình Python.

\subsection{Phương pháp nghiên cứu}

Nghiên cứu sử dụng các phương pháp: Điều tra, thu thập tài liệu, số liệu, bản đồ; Điều tra ngoại nghiệp; Kế thừa; Thống kê; Phân tích-tổng hợp; Chuyên gia; Bản đồ; Ứng dụng GIS; Ứng dụng Công nghệ thông tin. Trong đó, các phương pháp chính gồm:

\subsubsection{Phương pháp ứng dụng GIS}

Thực hiện việc chồng xếp các lớp bản đồ, phân tích các dữ liệu, truy vấn dữ liệu không gian và phi không gian phục vụ tra cứu thông tin theo yêu cầu. Đồng thời, ứng dụng phần mềm QGIS xây dựng công cư quản lý, tra cứu thông tin đường phố, số nhà tại địa phương.

\subsubsection{Phương pháp ứng dụng Công nghệ thông tin}

Việc ứng dụng công nghệ thông tin là rất cần thiết trong quá trình công nghiệp hóa - hiện đại hóa như hiện nay, tuy nhiên cùng với việc phát triển hàng loạt các phần mềm cũng như những ứng dụng được sử dụng quá phổ biến đòi hỏi người sử dụng phải có sự am hiểu nhất định về lĩnh vực, phần mềm mình quan tâm.

\subsection{Quy trình thực hiện}

Quy trình thực hiện được trình bày trong Hình 1 .

\section{Kết Quả và Thảo Luận}

3.1. Tìm hiểu khuynh hướng và thực tế việc đánh số nhà, tên đường tại địa phương thông qua thu thập tài liệu và điều tra khảo sát

3.1.1. Khảo sát, điều tra, thu thập tài liệu, số liệu, dữ liệu về việc đánh số nhà, tên đường tại địa phương

Quy trình khảo sát, điều tra, thu thập tài liệu, số liệu, dữ liệu được trình bày ở Hình 2.

3.1.2. Hiện trạng và khuynh hướng đánh số nhà, tên đường trên địa bàn

\section{- Hiện trạng}

Theo HCMCDOC (2012), số nhà được đánh số từ đầu đường đến cuối đường với bên trái là số lẻ và bên phải là số chẵn, trong các con hẻm sẽ được đánh theo thứ tự từ đầu hẻm đến cuối hẻm, trong đó tên bắt đầu bằng số nhà ngay góc phải đường chính, sau đó tối đa không qua 3 xuyệt (Bảng 1). Còn trường hợp một thửa đất có nhiều căn nhà thì số nhà được đánh kèm theo chữ cái $\mathrm{A}, \mathrm{B}, \mathrm{C}, \ldots$ Đây là địa bàn hầu như không có biến động nên số nhà ở phường chủ yếu là số nhà chính thức, còn trường hợp cấp tạm (cho các trường hợp không phù hợp với quy hoạch) thì chỉ ra thông báo tạm cấp nhưng hiện tại, nếu xuất hiện các trường hợp như thế thì hầu hết không được cấp, được quy định cụ thể tại mục 6 về đối tượng không được đánh số nhà.

- Khuynh hướng

$\diamond$ Nguyên tắc đặt tên đường: được đặt theo tên địa danh, các anh hùng dân tộc, tên nước ngoài theo đúng theo quy định của Bộ xây dựng. Các tuyến đường ở địa bàn đều là đường nội địa, được xác định rõ điểm đầu và điểm cuối. Các bảng tên đường đều rõ ràng, đặt nơi thoáng đãng, dễ quan sát và dò tìm (MOC, 2006).

$\diamond$ Nguyên tắc đánh số nhà: Theo HCMCDOC (2012), số nhà được đánh theo khuynh hướng đánh số nhà thông minh, cụ thể:

Đánh số nhà mặt đường và nhà trong ngõ, trong ngách theo dãy số tự nhiên $(1,2,3, \ldots, n)$ 


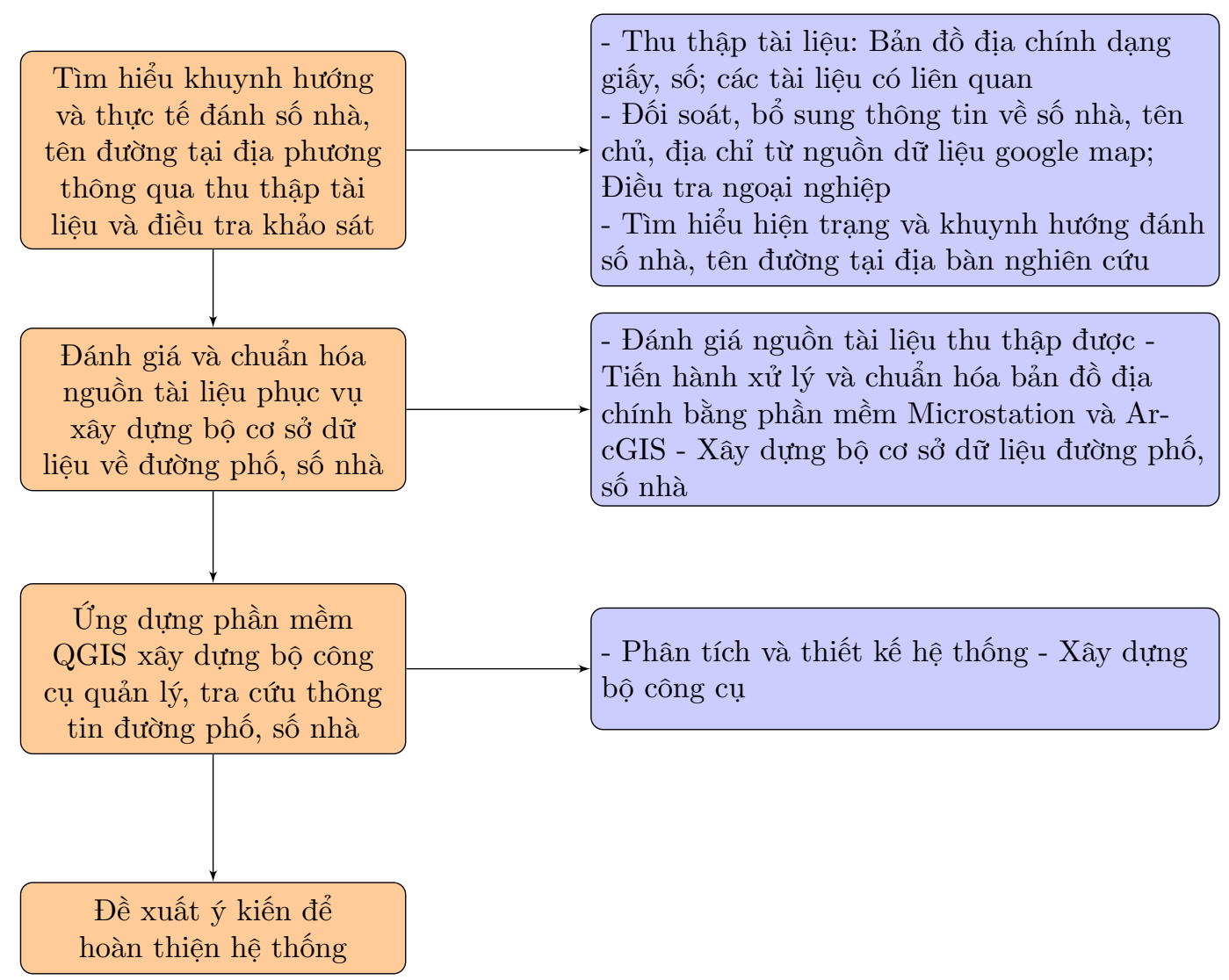

Hình 1. Quy trình thực hiện.

Bảng 1. Thống kê các tuyến đường trên địa bàn

\begin{tabular}{cccccc}
\hline STT & Tên đường & $\begin{array}{c}\text { Lòng đường } \\
(\mathrm{m})\end{array}$ & $\begin{array}{c}\text { Kết cấu mặt } \\
\text { đường }\end{array}$ & Điểm đầu & Điểm cuối \\
\hline 1 & Xa Lộ Hà Nội & 46 & Nhựa & Võ Văn Ngân & Đặng Văn Bi \\
2 & Võ Văn Ngân & 18 & Nhựa & Nguyễn Văn Bá & Đăng Văn Bi \\
3 & Đặng Văn Bi & 14 & Nhựa & Nguyễn Văn Bá & Võ Văn Ngân \\
4 & Hàn Thuyên (Đ1) & 25 & Nhựa & Nguyễn Văn Bá & Thống Nhất \\
5 & Hàn Thuyên $(Đ 2)$ & 10 & Nhựa & Thống Nhất & Đoàn Kêt \\
6 & Dân Chủ & 14 & Nhựa & Võ Văn Ngân & Đặng Văn Bi \\
7 & Thống Nhất & 14 & Nhựa & Võ Văn Ngân & Đăng Văn Bi \\
8 & Nguyễn Văn Bá & 16 & Nhựa & Võ Văn Ngân & Đặng Văn Bi \\
9 & Hữu Nghị & 12 & Nhựa & Võ Văn Ngân Hàn & Thuyên (Đ2) \\
10 & Nguyễn Khuyến & 16 & Nhựa & Thống Nhất & Đoàn Kết \\
11 & Đoàn Kết & 18 & Nhựa & Võ Văn Ngân & Khổng Tử \\
12 & Khổng Tử & 16 & Nhựa & Nguyễn Văn Bá & Dân Chủ \\
13 & Hòa Bình & 16 & Nhựa & Đặng Văn Bi & Khổng Tử \\
14 & Chu Mạnh Trinh & 10 & Nhựa & Đoàn Kết & Nguyễn Văn Bá \\
15 & Tagore & 16 & Nhựa & Nguyễn Văn Bá & Nguyễn Văn Bá \\
\hline
\end{tabular}

Nguồn: Phòng Quản Lý Đô Thị Quận Thủ Đức, 2017.

với thứ tự từ nhỏ đến lớn. Nhà bên trái lấy số lẻ $(1,3,5, \ldots)$, nhà bên phải lấy số chẵn $(2,4,6, \ldots)$.
Tùy theo khu vực mà chiều đánh số nhà được thực hiện từ Bắc xuống Nam, từ Đông sang Tây, 


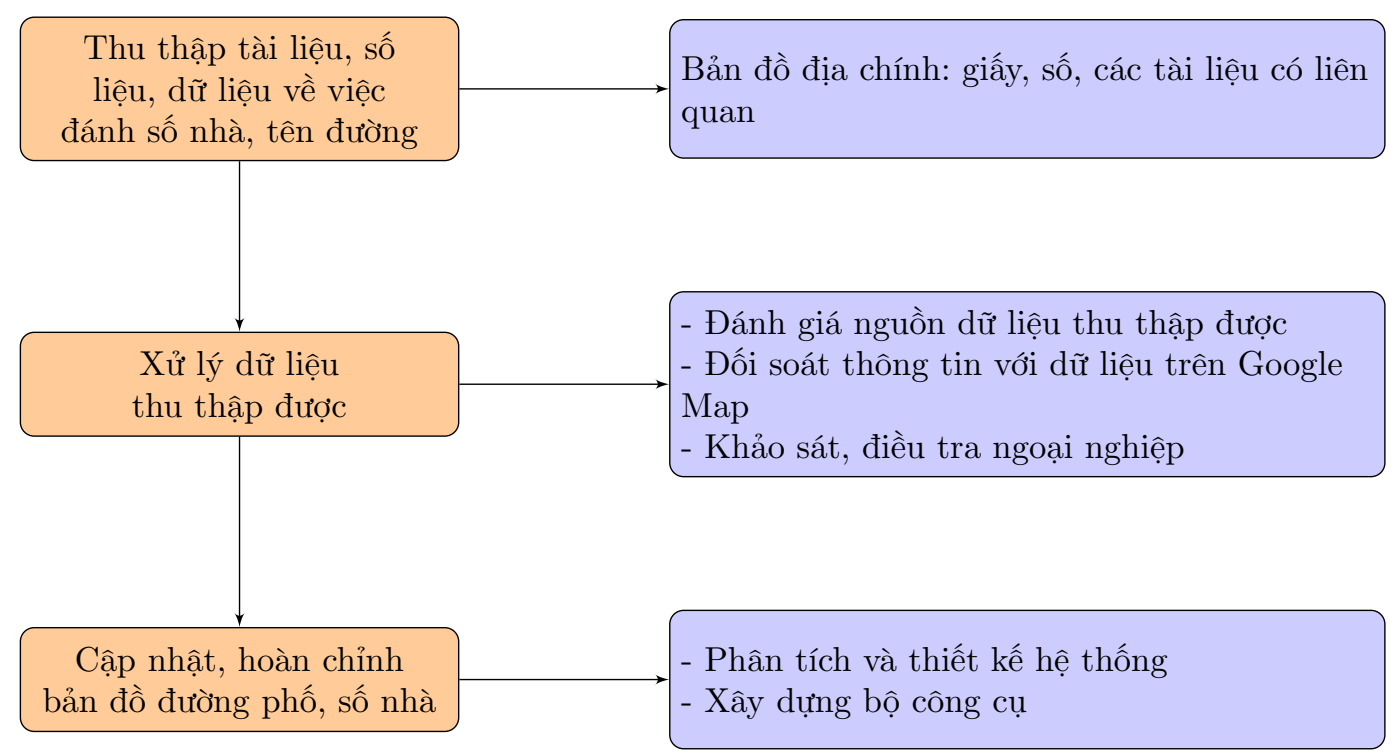

Hình 2. Quy trình khảo sát, điều tra, thu thập tài liệu, số liệu, dữ liệu.

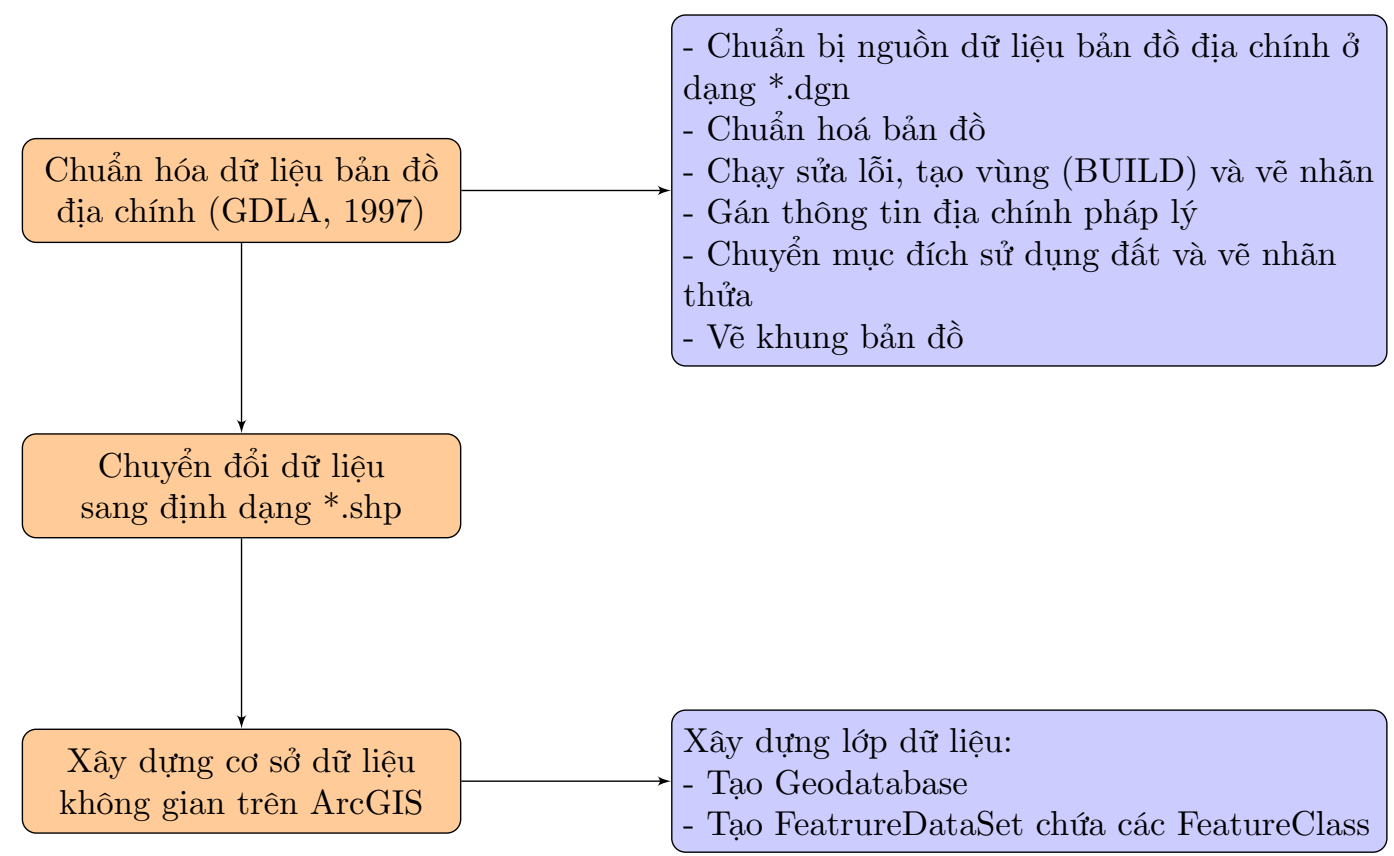

Hình 3. Quy trình xử lý và chuẩn hóa dữ liệu.

từ Đông Bắc sang Tây Nam, từ Đông Nam sang Tây Bắc.

Đánh tên nhóm nhà thì áp dụng các chữ cái in hoa của tiếng Việt $(\mathrm{A}, \mathrm{B}, \mathrm{C}, \ldots)$ sắp xếp theo thứ tự trong bảng chữ cái tiếng Việt với chiều sắp xếp của các nhóm nhà trong khu vực đó. Nếu các nhóm nhà nằm 2 bên trục đường giao thông nội bộ thì chiều đánh được xác định là: bên trái đường thì đánh tên $A, C, D, G, I, \ldots$, còn bên phải là $\mathrm{B}, \mathrm{D}, \mathrm{E}, \mathrm{H}, \mathrm{K}, \ldots$

$\diamond$ Quy định cấp số nhà: (1) cấp theo Kế hoạch của UBND quận, huyện; (2) cấp theo yêu cầu của gia đình. Dù cấp theo hình thức nào thì quy định về mẫu giấy chứng nhận và hình thức biển số nhà cũng giống nhau. Tùy vào từng loại biển báo mà kích thước được quy định cụ thể tại điều 14 của Quyết định số 05/2006/QĐ-BXD (MOC, 2006). 


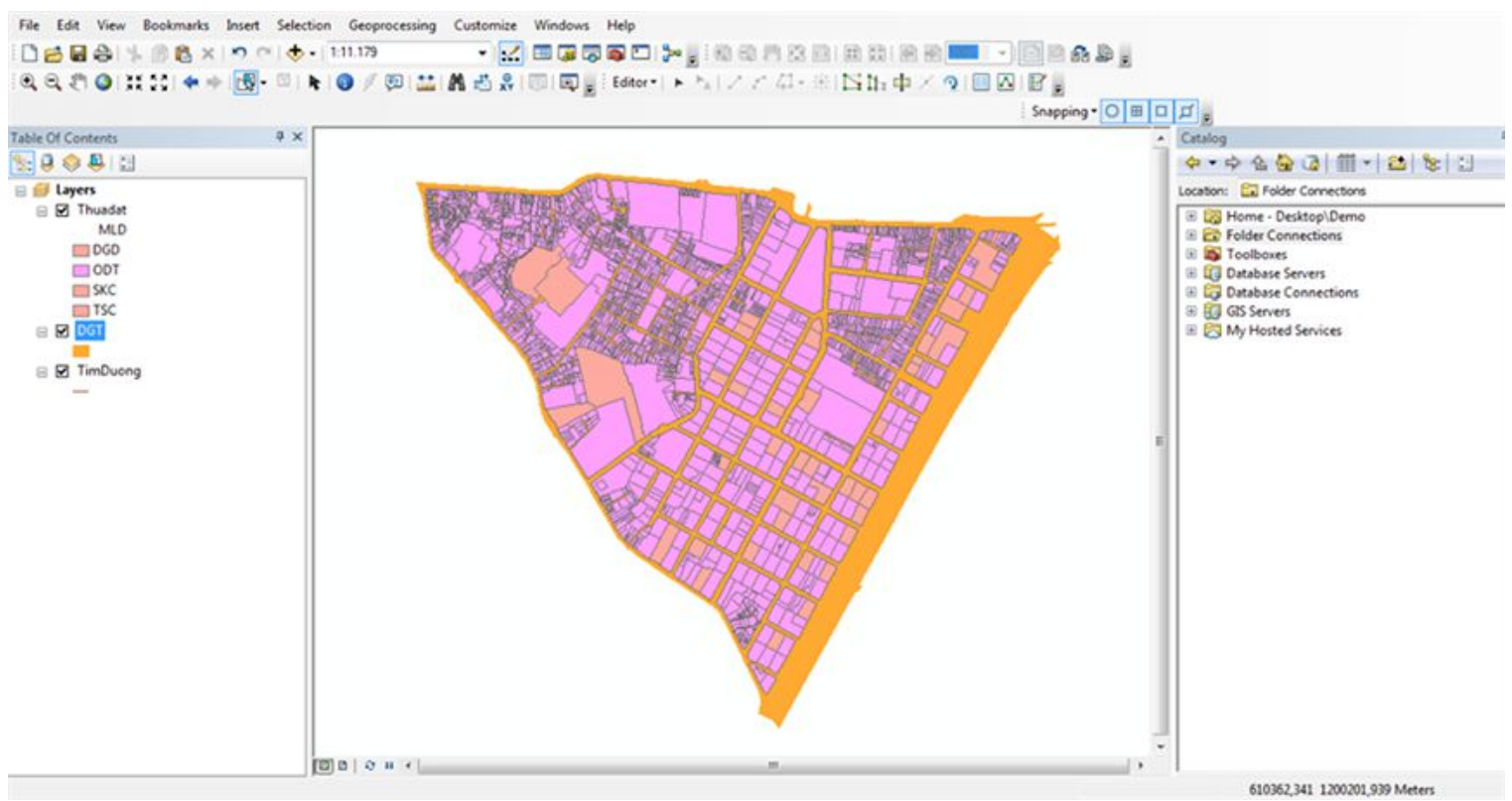

Hình 4. Kết quả chuyển đổi dữ liệu không gian.

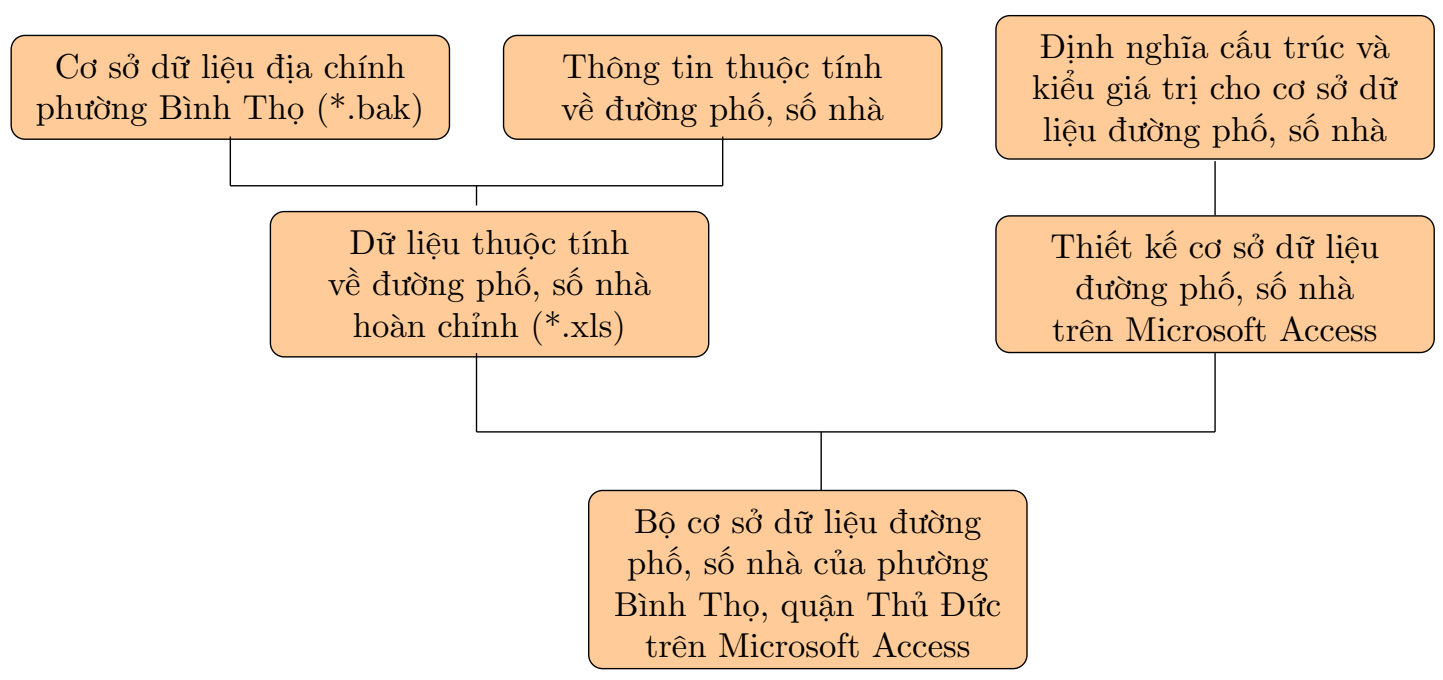

Hình 5. Quy trình xây dựng bộ cơ sở dữ liệu đường phố, số nhà.

3.2. Đánh giá và chuẩn hóa tài liệu phục vụ xây dựng bộ cơ sở dữ liệu về đường phố, số nhà

\subsection{1. Đánh giá nguồn dữ liệu đầu vào}

Tài liệu dạng giấy: có 4 tờ bản đồ địa chính tương đương với 4 khu phố của phường Bình Thọ, một số chỗ chữ viết khá mờ, không được cập nhật biến động thường xuyên nên độ chính xác thấp, cần được kết hợp với bản đồ số cùng với việc điều tra thực tế để đảm bảo độ tin cậy.

Tài liệu dạng số là 34 tờ bản đồ địa chính của 4 khu phố tại phường Bình Thọ, quận Thủ Đức có file *.dgn trên phần mềm Microstation. Bản đồ ban đầu chưa đầy đủ địa chỉ, cũng như chưa 


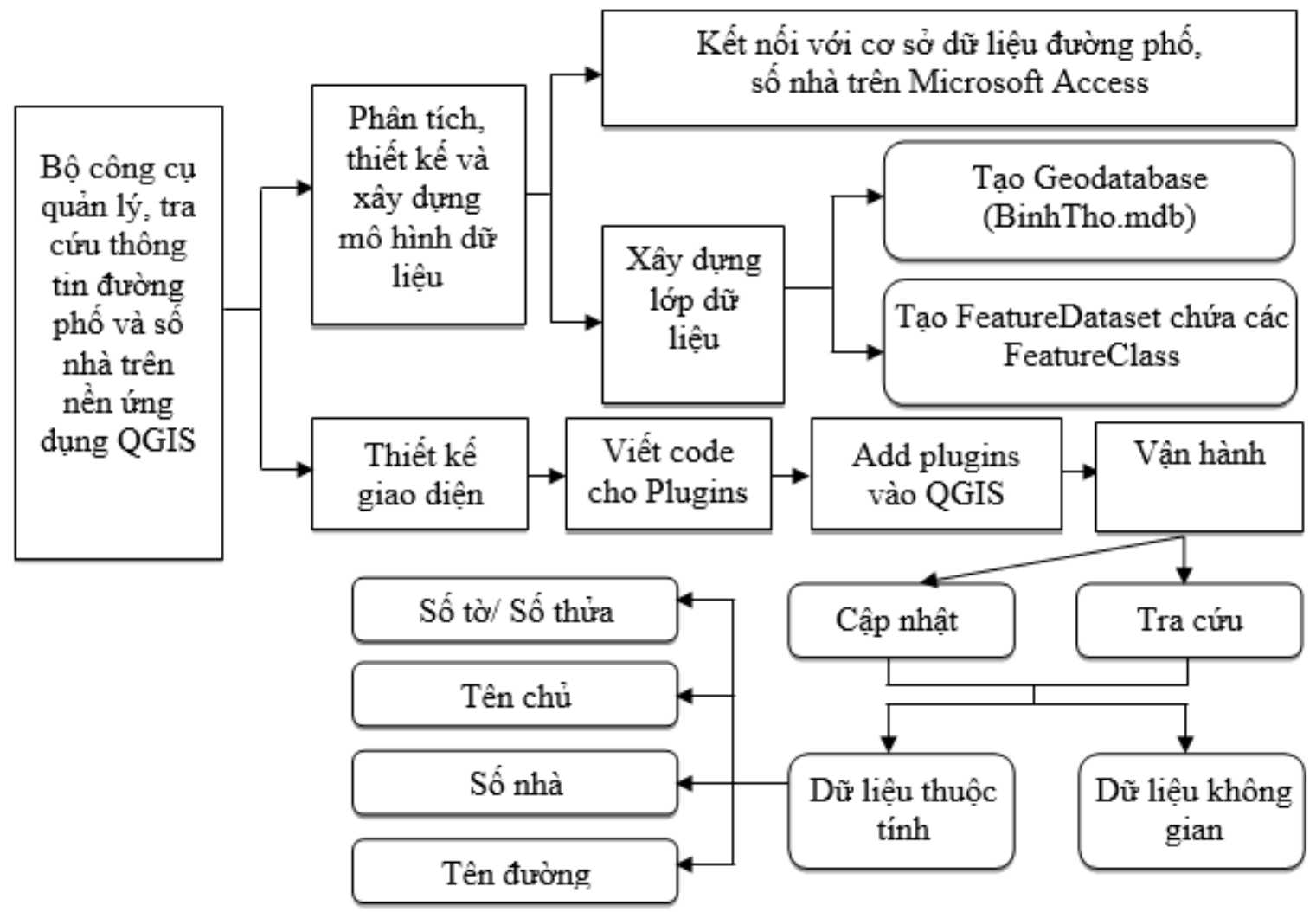

Hình 6. Quy trình xây dựng công cụ quản lý, tra cứu thông tin đường phố, số nhà.

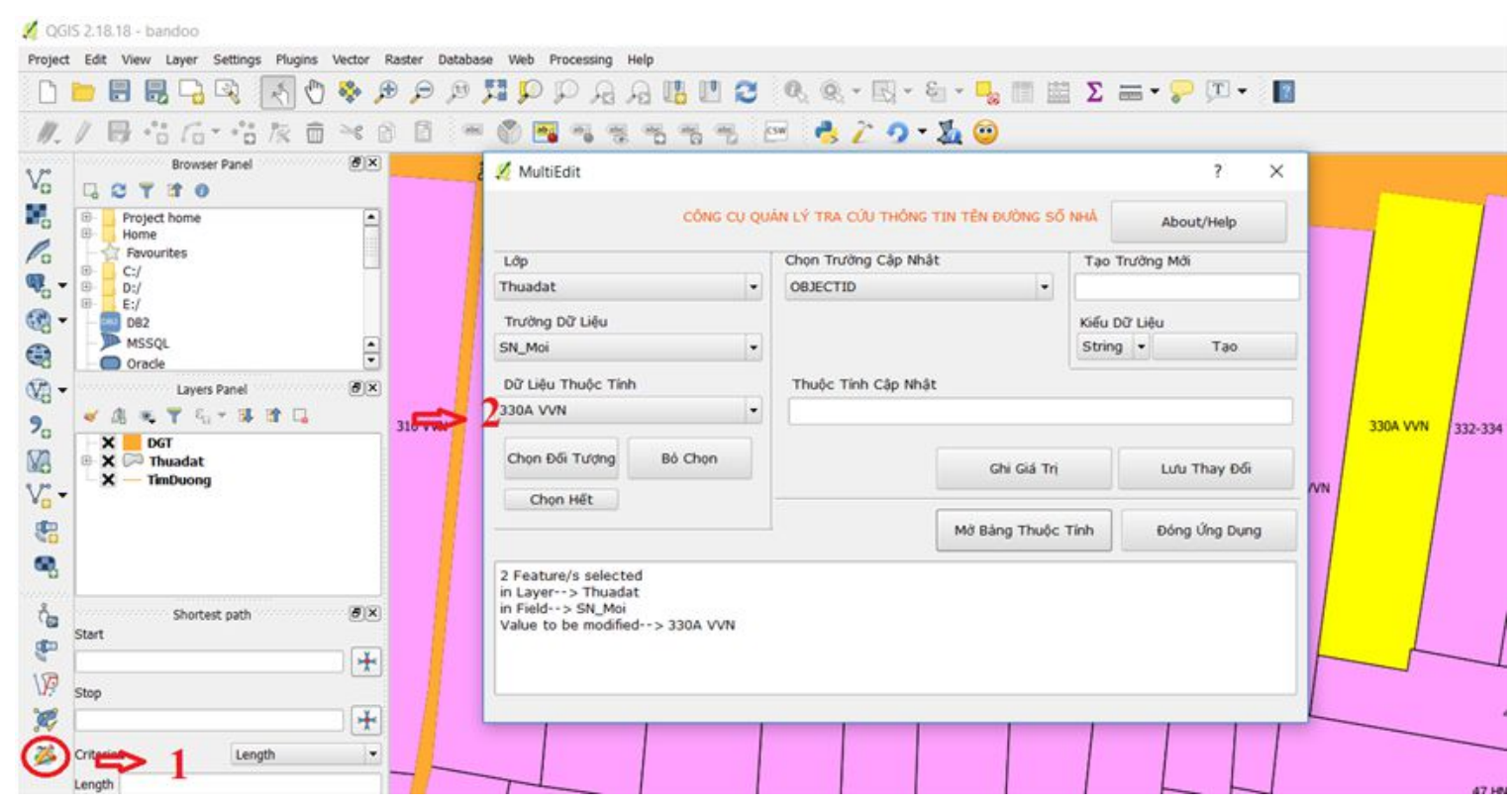

Hình 7. Giao diện công cụ quản lý, tra cứu thông tin đường phố, số nhà. 


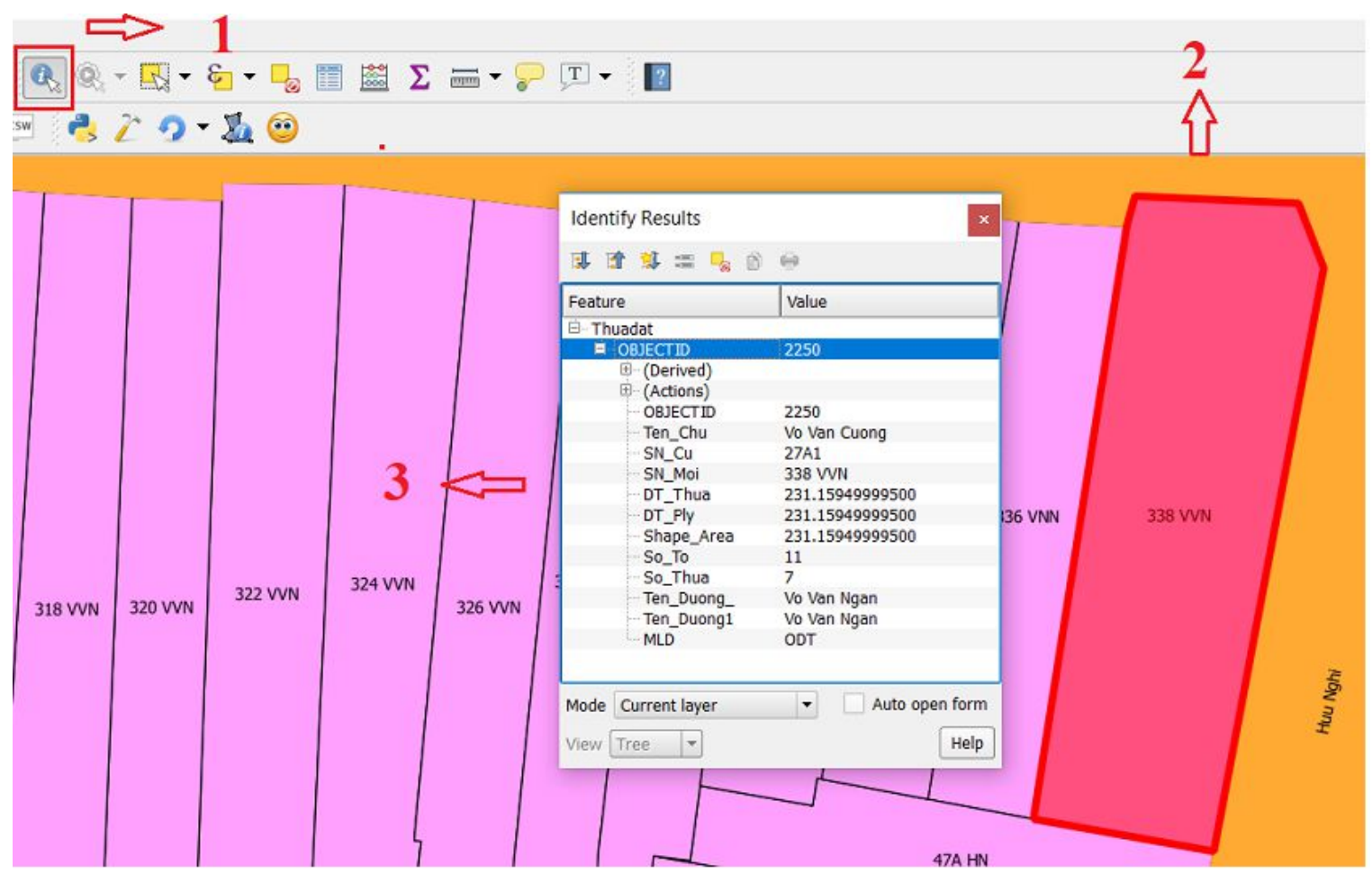

Hình 8. Giao diện tra cứu theo dữ liệu không gian.

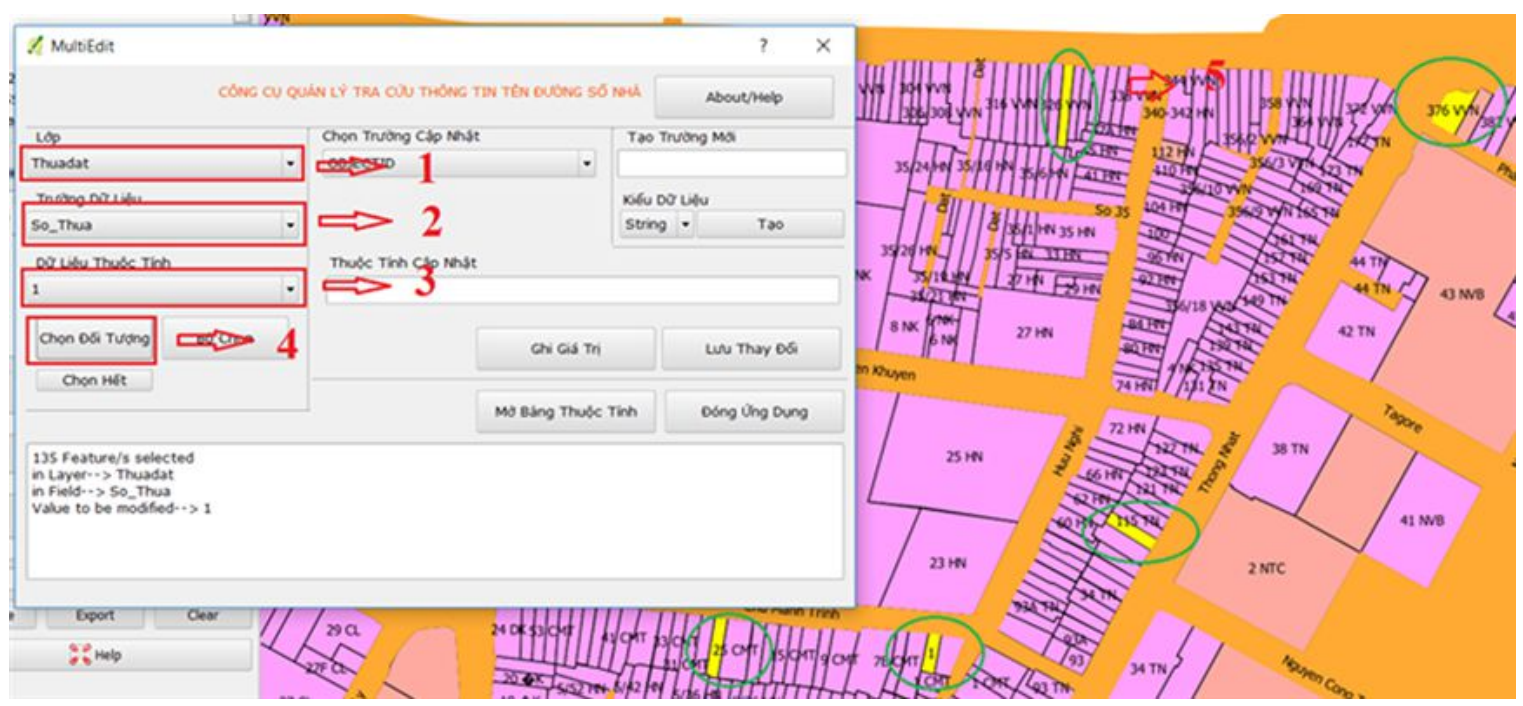

Hình 9. Kết quả tra cứu theo số hiệu thửa đất.

được chuẩn hóa.

Tóm lại, kết hợp với điều tra, khảo sát thực tế mới đảm bảo được nguồn dữ liệu đầu vào hoàn chỉnh, chính xác và có độ tin cậy cao để phục vụ cho việc xây dựng bộ cơ sở dữ liệu về đường phố, số nhà trên địa bàn. 


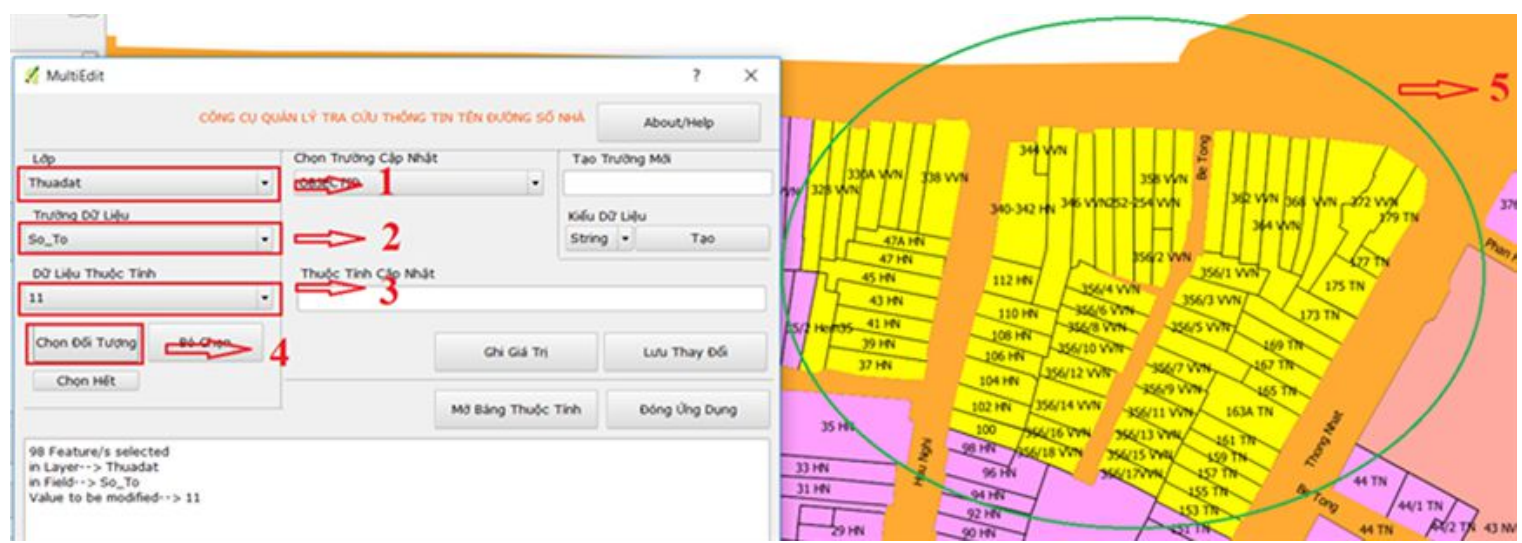

Hình 10. Kết quả tra cứu theo số hiệu tờ bản đồ.

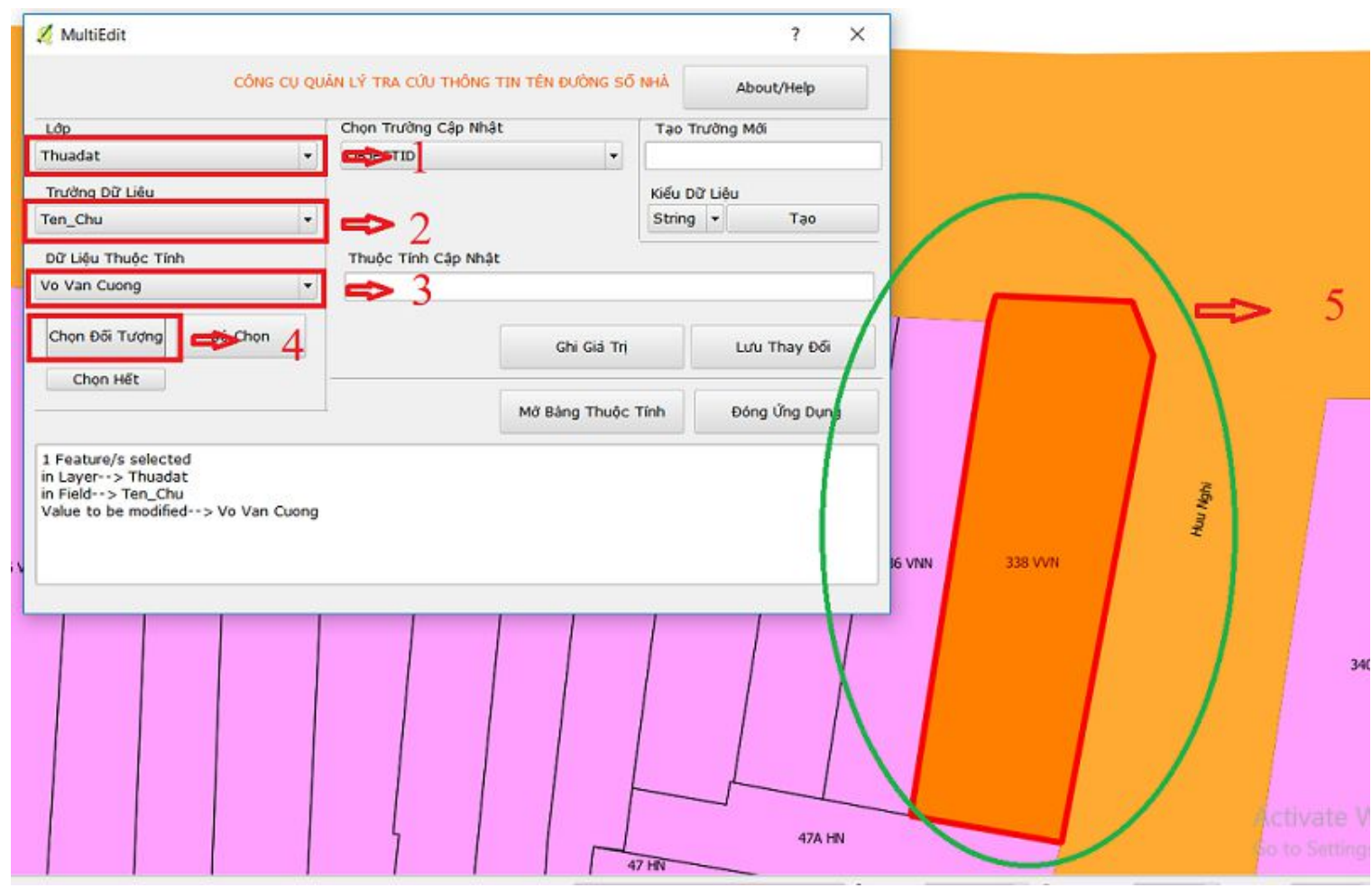

Hình 11. Kết quả tra cứu theo tên chủ sử dụng.

\subsubsection{Xử lý và chuẩn hóa dữ liệu}

Dữ liệu là thành phần quan trọng nhất, nên dữ liệu xây dựng phải chính xác, rõ ràng, dễ hiểu và gắn với yêu cầu thực tế của con người, hạn chế việc thiếu hoặc thừa dữ liệu (Dang, 2001). Việc chuẩn hóa dữ liệu và chuyển đổi dữ liệu không gian được trình bày trong Hình $3 \& 4$.
3.2.3. Xây dưng bộ cơ sở dữ liệu đường phố, số nhà cho địa bàn nghiên cứu

Bộ cơ sở dữ liệu quản lý đường phố, số nhà được xây dựng hoàn chỉnh với 2.394 bản ghi về thửa đất, 2.304 bản ghi về mục đích sử dụng đât, 2.358 bản ghi về người, 1.942 bản ghi về tài sản trên đất, 2.362 bản ghi về số nhà và 2.306 bản ghi về đường phố (Hình $5 \& 6$ ). 


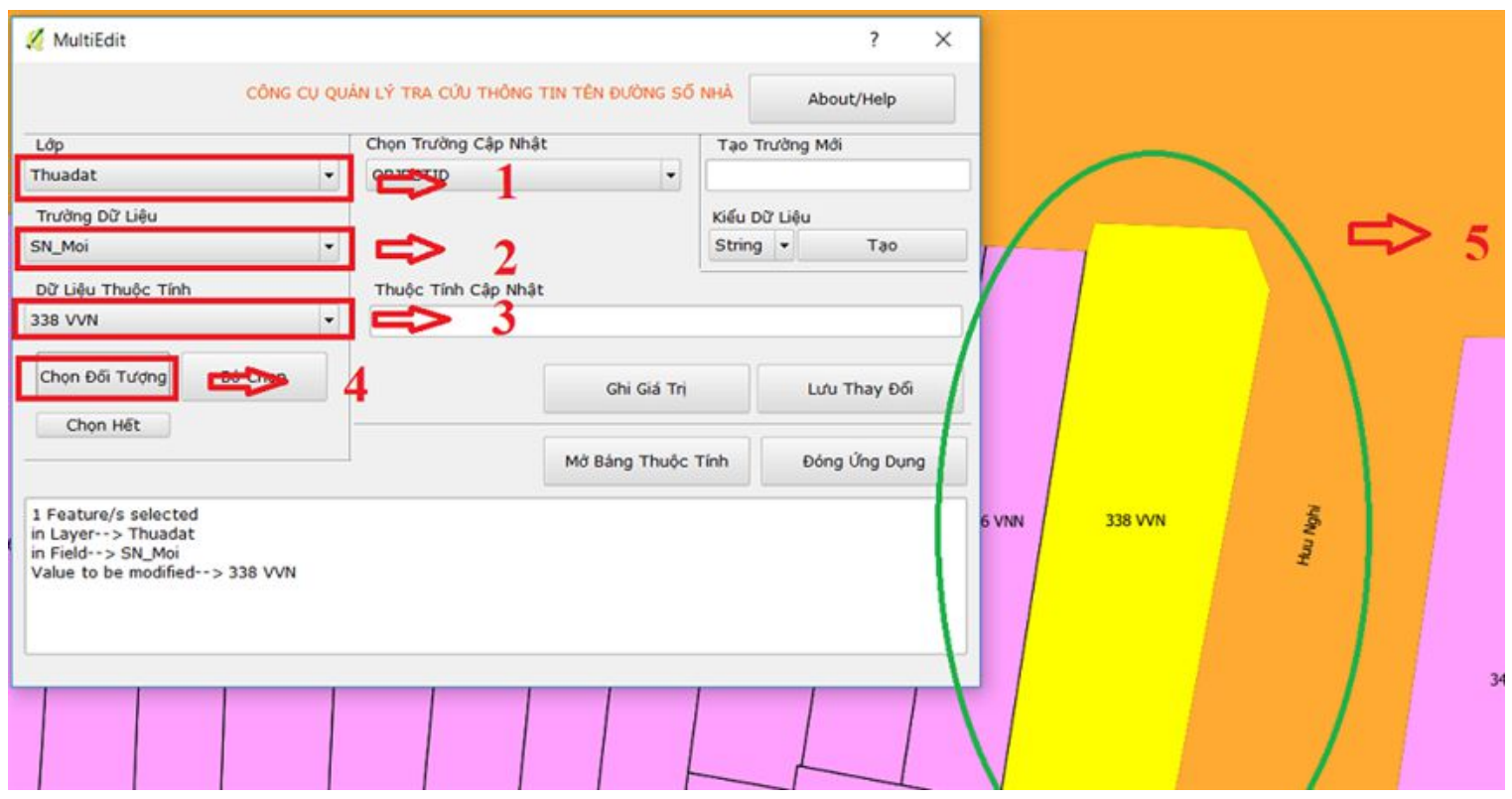

Hình 12. Kết quả tra cứu theo số nhà.

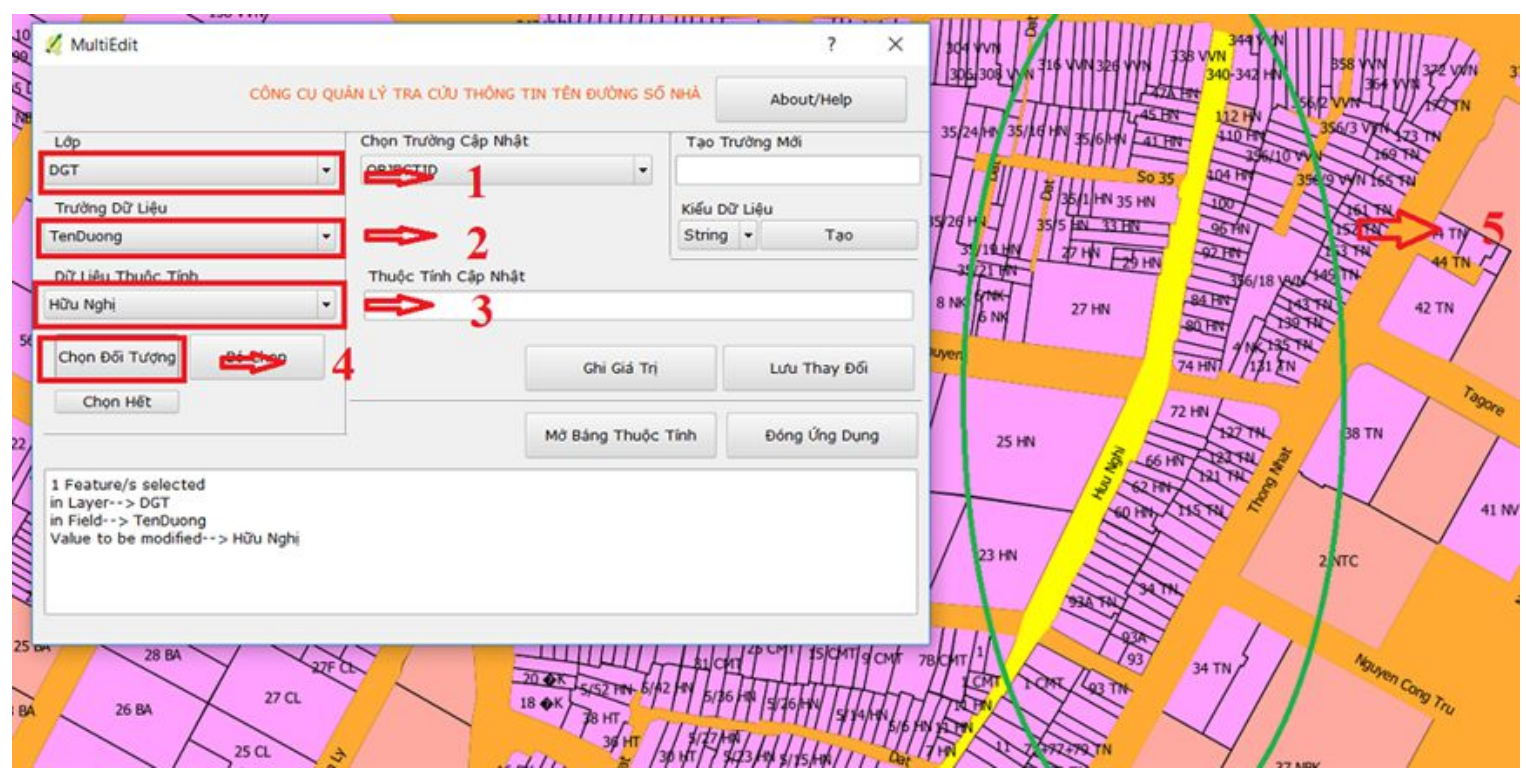

Hình 13. Kết quả tra cứu theo tên đường.

3.3. Xây dựng bộ công cụ quản lý, tra cứu 3.3.2. Xây dựng bộ công cụ quản lý, tra cứu thông thông tin đường phố, số nhà tin đường phố, số nhà

\subsubsection{Phân tích và thiết kế hệ thống}

Phân tích và thiết kế hệ thống trình bày ở Hình 6.
- Tạo giao diện công cụ (Hình 7: Ngoài việc kế thừa những chức năng hiển thị và tương tác bản đồ đã được tích hợp sắn trên QGIS (Westra, 


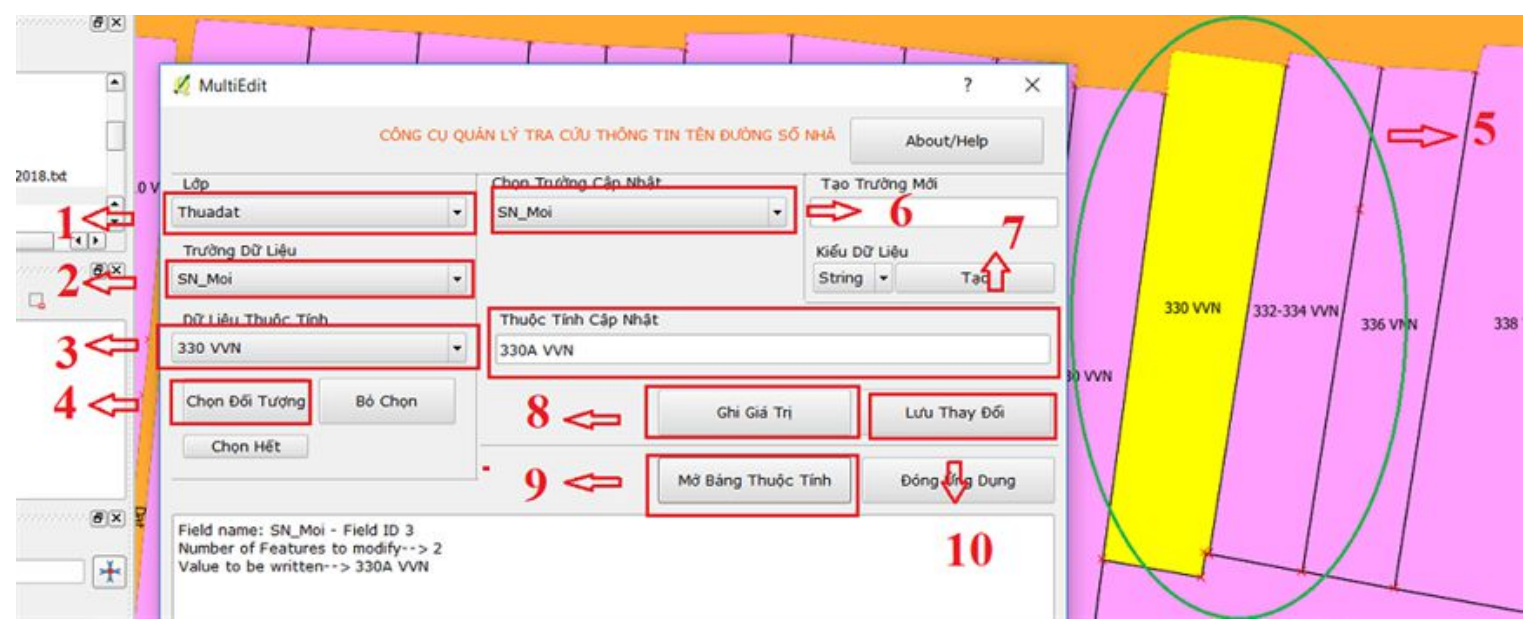

Hình 14. Kết quả truy xuất thông tin.

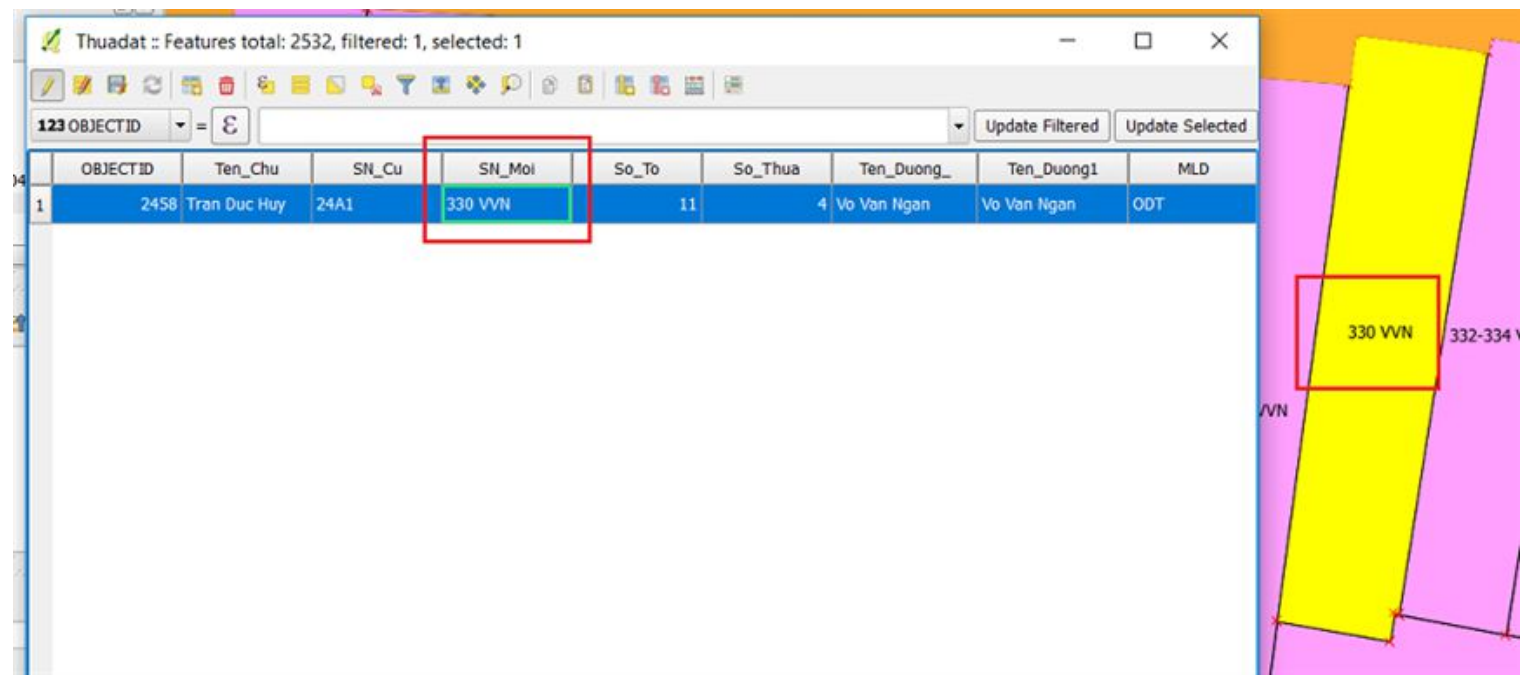

Hình 15. Dữ liệu trước khi cập nhật.

2014), nghiên cứu đã tạo được công cụ hỗ trợ các lệnh như tra cứu và cập nhật thông tin về thửa đất và đường phố, số nhà.

- Xây dựng chức năng tra cứu thông tin:

$\diamond$ Tra cứu theo dữ liệu không gian (Hình 8)

$\diamond$ Tra cứu theo dữ liệu thuộc tính: Chức năng tra cứu thông tin theo số hiệu thửa đất (Hình 9)

$\diamond$ Chức năng tra cứu thông tin theo số hiệu tờ bản (Hình 10)

$\diamond$ Chức năng tra cứu thông tin theo chủ sử dụng đất (Hình 11)

$\diamond$ Chức năng tra cứu thông tin theo số nhà (Hình 12) $\diamond$ Chức năng tra cứu thông tin theo tên đường (Hình 13)

$\diamond$ Chức năng cập nhật thông tin: Cho phép truy xuất thông tin của một thửa đất bất kì; cập nhật mới khi có thay đổi về một trong các nội dung như số tờ, số thửa, tên chủ sử dụng, tên đường, số nhà (Hình 14, 15 \& 16).

Với hệ thống quản lý thông tin tên đường, số nhà sẽ cung cấp cơ sở dữ liệu đầy đủ, chi tiết về mặt vị trí, diện tích, tên chủ sử dụng, tên đường, số nhà... kịp thời cập nhật thông tin biến động về số nhà tạo ra nhiều thuận lợi giúp cho công tác quản lý của Nhà nước về đất đai và nhà ở cơ sở hạ tầng và mỹ quan đô thị được triển khai 


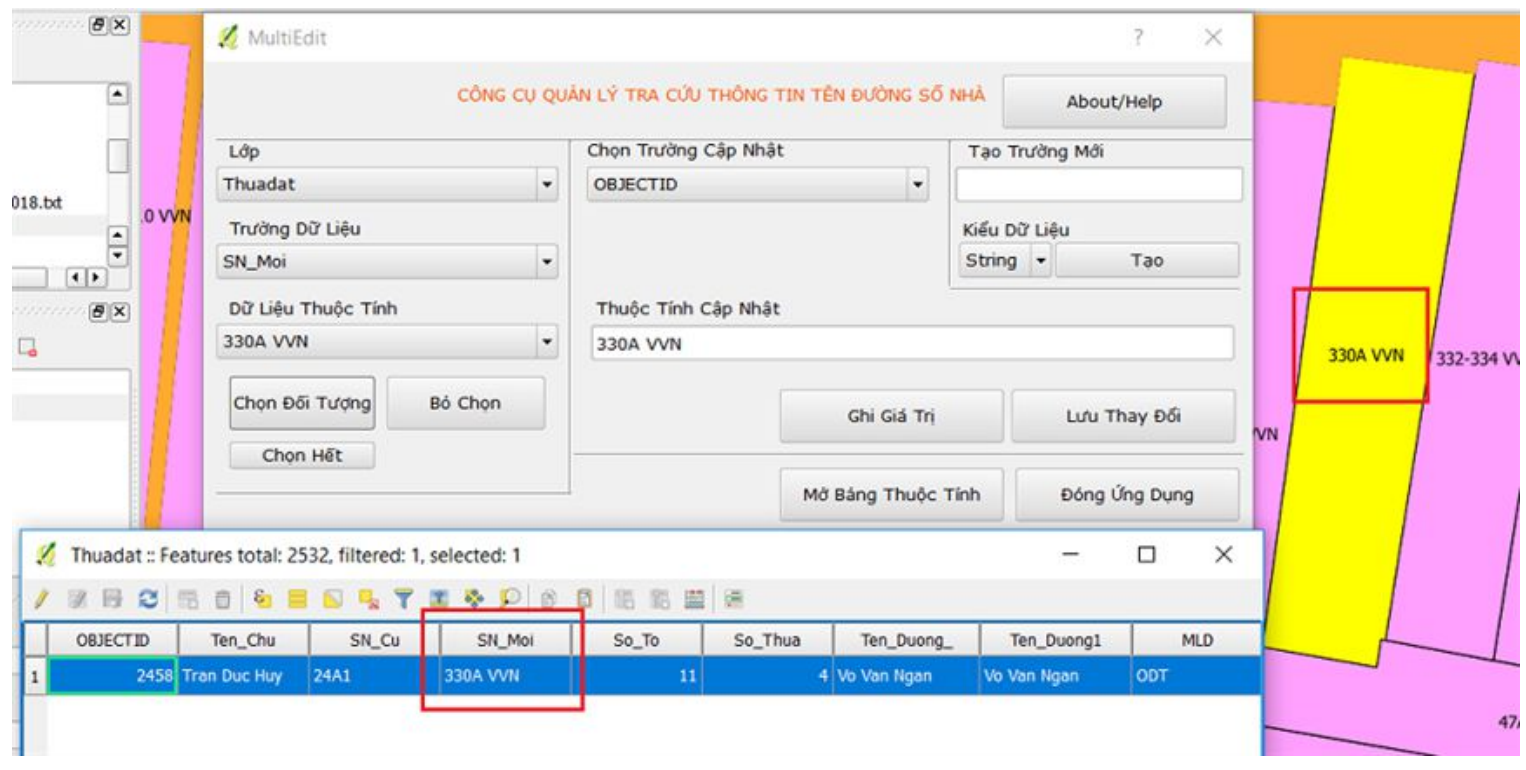

Hình 16. Dữ liệu sau khi cập nhật mới.

nhanh chóng.

Dữ liệu thuộc tính được bổ sung trên cơ sở dữ liệu của hệ thống qua đó có thể tra cứu, cập nhật, chỉnh sửa và khai thác các thông tin cần thiết một cách nhanh chóng và chính xác theo yêu cầu. Thực hiện việc tra cứu đơn giản theo các tiêu chí: thông tin liên quan đến thửa đất và thông tin về đường phố, số nhà. Kết quả tra cứu gồm hai thành phần là bảng dữ liệu thuộc tính và vị trí thửa đất tương ứng trên bản đồ.

Bảo đảm sự bảo mật dữ liệu: hệ thống quản lý người sử dụng thông qua hệ thống đăng nhập bằng password. Dữ liệu có thể lưu trữ ở nhiều dạng như trong máy vi tính, đĩa $\mathrm{CD}$, dĩa cứng hay USB và bảo quản thông tin được lâu dài (Westra, 2014).

\section{4. Đề xuất ý kiến hoàn thiện hệ thống}

Đầu tư máy tính có cấu hình đủ mạnh, phần mềm ứng dụng hiện đại.

Cần nâng cao thêm kiến thức chuyên môn và kỹ thuật cho các cán bộ ở địa phương.

Cập nhật thông tin thường xuyên, kịp thời, nhanh chóng và đầy đủ.

Giới thiệu cho các ngành, địa phương thấy rõ hiệu quả của GIS và phần mềm QGIS để cho họ thấy rõ sự cần thiết của việc sử dụng công nghệ trong quản lí.
Cần sự phối hợp của những tổ chức cung cấp số liệu và sử dụng số liệu.

Hoàn thiện hệ thống bản đồ địa chính số và cập nhật đầy đủ thông tin thuộc tính.

\section{Kết Luận}

Kết quả đề tài "Ứng dụng phần mềm QGIS quản lý cơ sở dữ liệu đường phố, số nhà trên địa bàn phường Bình Thọ, quận Thủ Đức, TP.HCM" đã đạt được như sau: (1) Tìm hiểu được khuynh hướng và thực tế việc đánh số nhà, tên đường tại địa phương thông qua thu thập tài liệu và điều tra khảo sát làm cơ sở để xây dựng cơ sở dữ liệu đường phố, số nhà; (2) Hoàn thiện dữ liệu không gian, cập nhật dữ liệu thuộc tính về địa chỉ nhà, tên đường trên nền bản đồ địa chính; (3) Hoàn thành bộ dữ liệu cơ sở dữ liệu đường phố, số nhà với 9 bảng dữ liệu thuộc 2 nhóm dữ liệu chính là: nhóm dữ liệu về đơn vị hành chính và nhóm dữ liệu về quản lý thông tin đường phố, số nhà; (4) Hoàn thành việc thiết kế, xây dựng công cụ quản lý cơ sở dữ liệu đường phố, số nhà với các chức năng: hiển thị, tra cứu và cập nhật thông tin theo đa chỉ tiêu về thửa đất (số tờ, số thửa, tên chủ sử dụng), tên đường và số nhà. Kết quả thử nghiệm cho thấy công cụ quản lý, tra cứu thông tin đường phố, số nhà hỗ trợ khá hiệu quả cho quá trình quản lý đất đai, xây dựng. Tuy nhiên, để công cụ quản lý thông tin đạt hiệu quả tối đa 
và có cơ sở nhân rộng mô hình trên địa bàn toàn quận thì cần thiết phải cập nhật đầy đủ và kịp thời tất cả các thông tin quản lý đất đai và đô thị trên địa bàn vào cơ sở dữ liệu địa chính của quận. Đồng thời tiếp tục hoàn thiện công cụ để kịp thời nắm bắt những đổi mới trong điều kiện công nghệ thông tin ngày càng phát triển như hiện nay.

\section{Tài Liệu Tham Khảo (References)}

Dang, D. V. (2001). Geographic information system (GIS). Ho Chi Minh City, Vietnam: Science and Technology Publishing House.

GDLA (General Department of Land Administration). (1997). FAMIS-CADDB Software System: Instructions for use (Software system in the cadastral industry for mapping, map and cadastral records management. Hanoi, Vietnam: GDLA Office.
HCMCDOC (Ho Chi Minh City Department of Construction). (2012). Official Letter No. 6278/SXD-QLN \&6 $C S$ dated on August 20, 2012 about guidance on numbering and house numbering. Ho Chi Minh City, Vietnam: HCMCDOC Office.

MOC (Ministry of Construction). (2006). Decision No. 05/2006/QD-BXD dated on March 8, 2006 about promulgating the regulation on numbering and numbering of houses. Ha Noi, Vietnam: Ministry of Construction.

Nguyen, T. C. (2014). Basic QGIS user guide. Ha Noi, Vietnam: Vietnam Administration of Forestry.

Westra, E. (2014). Building mapping applications with QGIS. Birmingham, UK: Packt Publishing. 